\title{
Correction to: Improved Butterfly Optimization Algorithm for Data Placement and Scheduling in Edge Computing Environments
}

\author{
Mehdi Hosseinzadeh • Mohammad Masdari • Amir Masoud Rahmani • Mokhtar Mohammadi • \\ Adil Hussain Mohammed Aldalwie • Mohammed Kamal Majeed • \\ Sarkhel H. Taher Karim
}

Received: 7 May 2021 / Accepted: 7 May 2021 /Published online: 2 July 2021

(C) Springer Nature B.V. 2021

\section{Correction to: J Grid Computing (2021) 19:14. https://doi.org/10.1007/s10723-021-09556-0}

The original version of this article unfortunately contains a mistake introduced during the production phase. The correct country of the affiliation of the author Amir Masoud Rahmani should be "Taiwan" instead of "Azerbaijan". In addition, the email address of Amir Masoud Rahmani was changed. The updated information is given below.

The online version of the original article can be found at https://doi.org/10.1007/s10723-021-09556-0

M. Hosseinzadeh

Institute of Research and Development, Duy Tan University, Da Nang 550000, Vietnam

M. Hosseinzadeh $(\bowtie)$

Mental Health Research Center, Psychosocial Health Research Institute, Iran University of Medical Sciences, Tehran, Iran e-mail: Hosseinzadeh.m@iums.ac.ir

\section{Masdari}

Department of Computer Engineering, Urmia Branch, Islamic

Azad University, Urmia, Iran

e-mail: M.masdari@ Iaurmia.ac.ir

\section{A. M. Rahmani}

Future Technology Research Center, National Yunlin University of Science and Technology, 123 University Road, Section 3, Douliou, Yunlin 64002, Taiwan

e-mail: Rahmania@Yuntech.edu.tw

\section{A. M. Rahmani}

Department of computer science, Khazar University, Baku, Azerbaijan
The original article has been corrected.

Publisher's Note Springer Nature remains neutral with regard to jurisdictional claims in published maps and institutional affiliations.
M. Mohammadi

Department of Information Technology, Lebanese French

University, Erbil, Kurdistan Region, Iraq

e-mail: Mukhtar@1fu.edu.krd

\author{
A. H. M. Aldalwie \\ Department of Communication and computer engineering, Cihan \\ university-Erbil, Erbil, Iraq \\ e-mail: Adil.mohammed@ cihanuniversity.edu.iq \\ M. K. Majeed \\ Department of Information Technology, Tishk International \\ University, Erbil, Iraq \\ e-mail: Mohammed.kamal@tiu.edu.iq \\ S. H. Taher Karim \\ Computer Department, College of Science, University of Halabja, \\ Halabja, Iraq \\ e-mail: Sarkhel.kareem@uoh.edu.iq
}

